Cuestiones de filosofía

ISSN: 0123-5095

Vol. 1 - No. 17

Año 2015

pp. 209-225

\title{
LUIS CABALLERO: ENTRE EL ÁNIMA ERÓTICA Y LA AFECCIÓN YACENTE
}

\author{
Luis Caballero: Between the Erotic \\ Soul and the Lying Affection
}

Milton Alberto Valencia-Herrera
valencia.milton@urosario.edu.co
Universidad del Rosario(Colombia)

Fecha de recepción: 11/11/ 2014

Fecha de evaluación: 24/02/2015

Fecha de aprobación: 15/09/2015

\section{Resumen}

La obra del pintor colombiano Luis Caballero muestra una progresión hacia una estética de lo mínimo; su búsqueda estilística se evidencia en cartas y declaraciones, donde habla acerca de la pintura de su época y expone su preocupación fundamental por la práctica artística. Para Caballero, esta práctica consistía en hacer ver; la pregunta fundamental que surge es: ¿qué es lo que se quiere hacer ver?; la respuesta, que debe buscarse en los cuadros del pintor bogotano, varía acorde con las influencias e inquietudes artísticas de Caballero. Alo largo del tiempo su obra manifiesta una tensión irresoluble entre la estética de la creación y la estética de la recepción. Estas estéticas, y los conceptos que las soportan, están presentes en toda su obra, pues a pesar de sus diferencias y limitaciones, es posible establecer relaciones de continuidad y dependencia. Para analizar la obra de Caballero se proponen tres etapas; en cada una el juego entre las dos concepciones sobre la estética se manifiesta de distintas maneras: (i) sus inicios responden a la influencia de Francis Bacon y manifiestan una inclinación a la estética de la creación; (ii) una búsqueda de un estilo personal y la apropiación de procedimientos del Barroco, y (iii) una estética mínima caracterizada por la reducción de los recursos pictóricos, que se compromete con una estética de la recepción. 
Palabras clave: Luis Caballero, Pintura, Preceptos y afectos, Estética de lo mínimo.

\begin{abstract}
The work of the Colombian painter Luis Caballero shows a progression towards a minimum aesthetics. Caballero's search for his own style, is revealed on his letters and statements about the painting of his time and his fundamental preocupation for the artistic practice. He strongly advocates for a painting that make us see. The important rising question would be: what is it that he wants us to see? The answer, which has to be found in his paintings, changes according to the influences and artistic questions of Caballero. His whole work is inhabited by a tension between the aesthetic of creation and the aesthetic of reception. Those aesthetics, and the concepts which explain them, are embedded in the work of the Bogotanean painter. Despite the differences and limitations of both, it is possible to establish some relations of necessity and complementation between them. In order to study the work of Caballero, this article proposes three periods. In each of these periods the tension between the two ways of understanding aesthetics manifests itself in different manners: (i) his beginning, which is under the influence of Francis Bacon manifest a strong movement towards the aesthetic of creation; (ii) the quest for a personal stile and his appropriation of the Baroque technics and (iii) the aesthetics of the minimum, identified by the reduction of pictorial resources and deeply engaged with the aesthetics of reception.
\end{abstract}

Key words: Luis Caballero, Painting, Precepts and Affects, The MinimumAesthetics.

\title{
1. INTRODUCCIÓN
}

Yo quisiera poder realizar una imagen que se imponga tanto y aún más que la realidad. Una imagen que concentre en sí misma toda la fuerza, toda la sensualidad, todo el drama y toda la violencia de la realidad.

Si un cuerpo me emociona, ¿cómo hacer para que la imagen del dibujo tenga el mismo poder de emoción?

(Caballero, 1995, p. 10)

¿Cómo hablar de una obra de arte sin apresarla conceptualmente?, ¿cómo superar la paradoja de una estética que reniega de una poética y que al hacerlo no puede determinar a priori las condiciones del juicio del gusto? (Lyotard, 1996); estas 
preguntas adquieren especial relevancia a la hora de enfrentarse a la obra del pintor colombiano Luis Caballero Holguín. A pesar de su reconocimiento tanto a nivel nacional e internacional, la obra del pintor bogotano, nacido en 1943, ha sido poco estudiada. En este texto me propongo realizar unos comentarios con ocasión de la obra de Caballero, dejando que sean los propios cuadros los que sirvan de guía al análisis, en lo posible, sin imponer un determinado esquema conceptual.

La hipótesis que quiero demostrar en estas líneas es la siguiente: Caballero se inclina por una estética de lo mínimo, en la cual la creación de sensaciones resulta fundamental. El propio pintor dirá que "pintar no es hacer cuadros, pintar es expresarse por medio del color y de las formas. Crear con estos elementos algo que exista y que tenga vida propia. Algo que emocione, que inquiete y que tenga una verdadera presencia" (Segura, 1991, p. 35). Ahora bien, ¿por qué es tan importante la creación de sensaciones? y ¿qué relación guardan esas sensaciones con la producción de emociones inquietantes? La respuesta, que por el momento será solo sugerida, es la segunda hipótesis que presenta este artículo y que, necesariamente, acompaña a la estética mínima: Caballero busca despertar el ánima a través de acontecimientos sensibles. En ese sentido, la obra del pintor se mueve cada vez más hacia una estética de la recepción ${ }^{1}$, en la que Caballero busca ponerse en el lugar del espectador, pero sin dejar de lado la creación de sensaciones.

Así, en el pintor bogotano se manifiesta una tensión entre una estética de la creación, que domina los primeros años de su producción artística y que entiende la obra como un ser de sensación que existe en sí (Deleuze \& Guattari, 2013), y la obra como un acontecimiento sensible que anima a alguien, el cual mueve al espectador (estética de la recepción). En los cuadros de Caballero esta tensión no se resuelve con la creación de una nueva estética que sintetice los opuestos; tampoco con el abandono de alguno de los dos extremos a favor de consagrarse exclusivamente a alguno de ellos; la tensión se mantiene siempre, ambas estéticas juegan y se complementan sin fusionarse. ¿Cómo se complementan?, ¿cuáles son los límites de cada una?, ¿cuáles sus vasos comunicantes?; estos problemas están estrechamente

1 Concepto desarrollado por Hans-Robert Jauss (1978), quien, tomando algunas nociones de Hans Gadamer (particularmente la fusión de horizontes), hace hincapié en la relación de la obra literaria con el lector. Es esa relación entre obra y espectador la que este texto busca rescatar en la última etapa de la obra del pintor bogotano. A diferencia de una estética de la creación, ocupada de qué hace a una obra de arte ser tal y de su relación con el artista, la estética de la recepción hace énfasis en la relación de los espectadores con la obra. 
relacionados con las hipótesis que quiero demostrar y serán tratados en el desarrollo del texto.

Este texto hace un recorrido por la obra de Caballero; sin embargo, aquí surge un primer problema, pues los críticos de arte que han analizado la obra de este autor la catalogan de distintas maneras, por lo que podemos encontrar tres, cuatro o cinco periodos, dependiendo de la fuente consultada. Aunque sería interesante una discusión sobre los criterios de periodización, eso alejaría el texto de sus objetivos; por ello, y debo confesar que de forma un poco arbitraria de mi parte, seguiré la periodización sugerida por María Margarita Malagón-Kurka (2012).

\section{Primero años. Influencias y búsQuedas}

Naturalmente, la imagen sagrada pasó a ser laica. Y del cristo, hijo de Dios, pasé al hombre. La parte sobrenatural se perdió. Hoy lo sagrado no es Dios, sino los seres humanos. La imagen sagrada es para mí el cuerpo humano. Y en él resumo todo lo que me interesa

(Caballero, 1990, p. 21)

Desde muy joven y gracias a su padre, Caballero se inició en el mundo de la pintura (Segura, 1991); luego de un breve periodo como estudiante de Bellas Artes en la Universidad de los Andes, en 1962 se va a vivir con su familia a París; allí continúa con su formación artística, en la academia de la Grande Chaumiére. Las obras de este primer periodo están muy influenciadas por el trabajo del pintor anglo-irlandés Francis Bacon: "Bacon el único, el genial, el monstruo, el visionario, el profeta, ante el cual inclino yo mi frente y por desgracia también la pintura" (Caballero, 2014c).

Si bien a través del tiempo Caballero experimentó, formal y materialmente, con distintos materiales y técnicas, hay una constante temática que atraviesa toda su pintura: el desnudo. Obsesivo, Caballero intenta trasmitir en las contorsiones de los cuerpos una intensidad y una afección que subsistan por sí mismas. Beatriz González dirá que en esta etapa de su obra "quiere denotar el poder del artista al transmitir su íntima energía a través del espacio, las líneas, las formas y los colores” (1991, p. 22).

Caballero está más próximo en este momento a lo que Gilles Deleuze y Félix Guattari han denominado perceptos y afectos ¿Por qué hablar de perceptos en lugar de percepciones? Deleuze afirma que el percepto es un conjunto de percepciones y 
sensaciones que sobreviven a aquel que las experimenta (1966). En ese orden de ideas, lo que Caballero ofrece no es la representación de algo, sino un ser de sensaciones que le sobrevive y que deja ver las líneas de fuerza que atraviesan a sus figuras (Deleuze \& Guattari, 2013). Sin embargo, hay un descontento del artista con sus cuadros; de hecho, más adelante afirmará que eran "formas demasiado gratuitas, a las que le faltaba una necesidad (o mejor) había encontrado una manera de pintar, pero no qué pintar" (Segura, 1991, p. 33).

¿Qué es lo que falta? En primer lugar diré que los cuadros están muy cargados de color y líneas. Como veremos más adelante, en cada periodo la supresión de elementos es cada vez mayor y más próxima a una estética de lo mínimo en la que con pocos elementos se consigue transmitir una sensación que nos anima. En segundo lugar, estas obras no producen necesariamente un despertar del ánima debido a que responden principalmente a una creación de sensaciones que son arrancadas de la percepción y contenidas en los materiales de la obra (Deleuze \& Guattari, 2013), y no a una preocupación por lo que pasa con el espectador. Surge entonces la primera manifestación de la tensión entre estética de la creación y estética de la recepción, que anunciamos en la introducción.

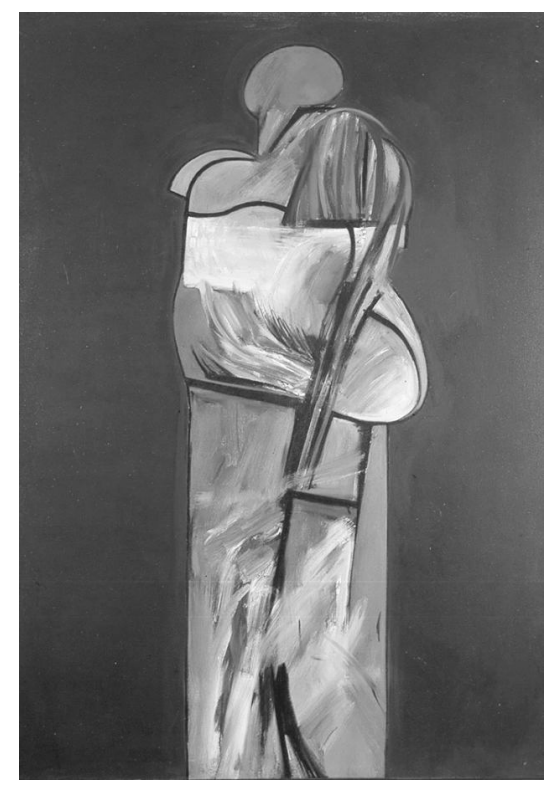

Fig. 1. Sin título, 1968. Óleo sobre tela. 170 X $120 \mathrm{~cm}$. 
Con el término ánima quiero poner de manifiesto aquello de lo que nos habla JeanFrançois Lyotard en Moralidades posmodernas, y que define como algo que solo existe en la medida en que es afectado. La sensación que nos afecta es una aisthesis que modifica nuestra disposición al bienestar o al malestar; en ese sentido, el ánima que aquí mencionamos no tiene ninguna connotación religiosa o espiritualista. El ánima permite realizar el paso que el propio Caballero busca de lo sagrado-divino a lo sagrado-profano.

En ese sentido, se empiezan a hacer patentes los límites de los conceptos de afecto y percepto: su relación con el espectador; más adelante volveré sobre este punto. Lo que aquí me interesa señalar es el hecho de que la creación de un ser de sensaciones no es suficiente, falta lograr la emoción. No pretendo aquí afirmar que las formas de Bacon en las que se inspira Caballero fracasen al momento de lograr esa disposición al malestar, porque, en realidad, sí la producen (Deleuze, 2002); lo que quiero decir es que el arte de Bacon, como técnica, no satisfizo al artista, y por ello tuvo que abandonarla para ir en busca de otras maneras de lograr una disposición anímica que emocione e inquiete. En una carta de mayo de 1963, el pintor le escribe a su amiga Beatriz González: "Yo aquí estoy desesperado porque nada que aprendo a dibujar, pero eso es lo de menos, aprenderé, estoy seguro; pero es que hay momentos en que me entra una desesperación, una desilusión de no poder hacer lo que quiero, terrible" (2014a, p. 59). Esta inseguridad en su propia capacidad artística se repite a lo largo de sus primero años; por ejemplo, en carta del 17 de noviembre de 1969 Caballero dice: "No es pedantería, de veras, estoy muy preocupado y me inquieta ver que la pintura en general y la mía en particular se revela incapaz de producir emociones, de crear mundos, de interpretar ideas" (2014b, p. 121).

Hay entonces una diferencia entre el concepto de afecto y el de ánima. Se pueden crear perceptos y afectos en un ser de sensaciones (obra) que, una vez creado, no depende del creador. Pero captar la fuerza del movimiento de estos cuerpos no implica lograr ese acontecimiento que lanza al espectador al dolor o al placer. Los afectos son necesarios para la existencia de la obra, pero no son suficientes para lograr afectar al espectador. Dicho de otra manera, a los afectos y perceptos creados por Caballero les hace falta una intensidad que, en cambio, es visible en la obra de Bacon. Tal vez fue esa falta de intensidad de sus imitaciones baconianas lo que motivó en Caballero el abandono de este estilo. Lo que sí sabemos, por las declaraciones del propio pintor, es que su búsqueda de otro estilo estaba motivada por el deseo de superar lo que Caballero llamaba el "esteticismo", es decir, hacer algo más que pintar "cuadros bonitos” (2014d, p. 109). Así, el autor entra en una 
segunda etapa, a la que el crítico francés Jean Leveque se refiere de la siguiente forma: "Allí donde Bacon la encierra [la figura] en la geometría de un infierno mental, de la locura por llegar (ya toca la puerta, su abominable miasma ya impregna el espacio), Caballero disuelve los límites del entorno. No son más que sombras que se anuncian, pero se retuercen voluptuosamente, también ellas. En Bacon la amenaza es aquella de un vicio que perdura; en Caballero, la de la disolución; eléxtasis de la supresión de los límites corporales" (Segura, 1991, p. 32).

\section{El PLiegue barroco}

Hay pintores que pintan desnudos como quien pinta una cafetera. Son los estetas que piensan que lo importante es hacer un cuadro. Cada pintor ha pintado por lo menos un desnudo en su vida, pero yo creo que casi siempre han olvidado lo esencial, y es que un desnudo se debe pintar sensualmente, eróticamente, amorosamente

(Segura, 1991, p. 43)

La segunda etapa de la obra de Caballero coincide con su decisión de radicarse en París, en el año de 1968; es en este momento cuando la obra del pintor colombiano experimenta un giro hacia el dibujo y los temas religiosos de la pintura renacentista y barroca (Malagón-Kurka, 2012). El viraje a los temas religiosos le ofrece a Caballero un procedimiento propio del Barroco, descrito por Deleuze como un mundo dividido en dos pisos separado por un pliegue que actúa en los dos lados según un régimen diferente (2012). En el pliegue Barroco hay una reconciliación de la oposición radical entre la gravedad física de los cuerpos y la elevación religiosa. Esos vectores (gravedad/elevación) pasan a formar parte de un mismo mundo en el cual el alma y el cuerpo, por inseparables que puedan ser, no dejan de ser realmente distintos (Deleuze, 2012).

El modo como Caballero se apropia de ese pliegue barroco consiste en poner la carne en el primer plano y hacer un pliegue del cuerpo en el alma; en efecto, lo sexual y lo erótico, que saturan los cuerpos semidesnudos, muestran la paradoja de la vida humana: no hay elevación sin caída.

Aquí Caballero está mostrando la experiencia de su condición de homosexual en una sociedad patriarcal y conservadora como lo era la Colombia de los años sesenta y setenta. Los cuerpos de sus obras muestran una mística encarnada, un impulso erótico que tiene como inspiración su propia vida privada. Pero ¿no es contradictorio 
hablar de una mística encarnada?, ¿qué papel juega lo erótico y lo sexual? No hay contradicción en la mística encarnada, se trata de un pliegue que permite al cuerpo llegar al alma a través de lo erótico; esta mística es una profanación de la iconografía cristiana y una secularización que obtiene su fuerza de su condición de homosexualtransgresor. Lo erótico y sexual está en este contexto asociado con la idea de la petit mort o pequeña muerte como estado de relajación subsiguiente a la eyaculación y que permite un corto periodo de trascendencia (Apollinaire, 2001). Esta conexión entre el coito del cuerpo yacente y lo místico-trascendente no es nueva en el arte, y se puede encontrar en obras literarias como Alcoholes, del poeta francés Gillaume Apollinaire; tampoco es desconocida para Caballero, quien realizó varios dibujos en pequeño formato de cuerpos masculinos en el momento de la exultación sexual, del coito desfalleciente (Caballero, 2010).

Las obras de esta época llevan a Caballero a mostrar que la sensualidad y el erotismo pueden estremecer los extremos de las cuerdas de la habitación de arriba (el alma); estos dos pisos son diferentes: (i) la habitación cerrada, que es pura interioridad, autonomía, libertad, y (ii) la fachada, que es una exterioridad sometida a la materia, a las leyes físicas (Deleuze, 2012a). El cuerpo desnudo y yacente, inspirado en motivos religiosos, como la pietá o el descenso de la cruz, forma parte de la fachada. Pero el éxtasis que alcanzan las figuras de la fachada nos permite entrever ese espacio de libertad pura y sin límites, la habitación cerrada. El pliegue barroco es entonces la forma como elementos heterogéneos habitan un mismo espacio sin contradicción. Cuerpo y alma son diferentes, pero no se presenta uno sin la otra. Profundicemos un poco más acerca de la relación entre ambos.

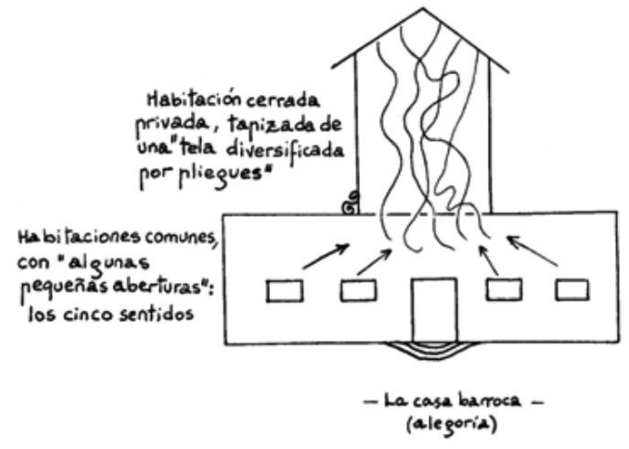

Ilustración de Gilles Deleuze tomada de El pliegue, Paidós (Barcelona: 2012) 


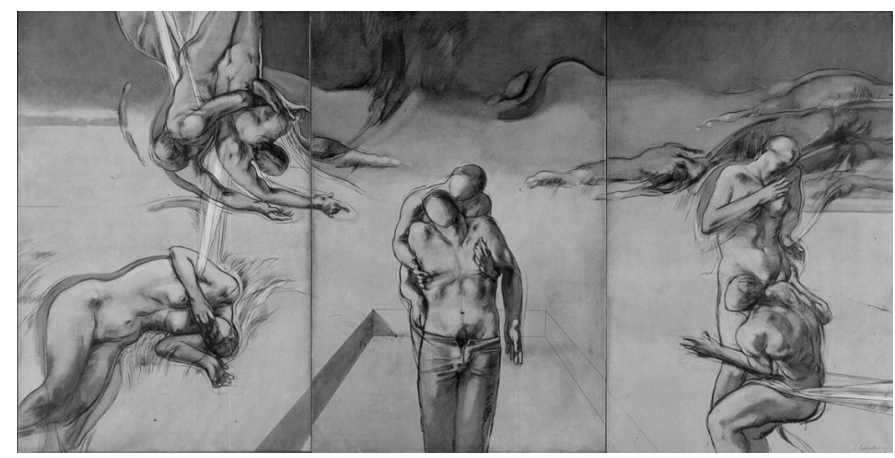

Fig. 2. Sin título, 1973. Óleo sobre papel entelado. 195 X $390 \mathrm{~cm}$.

Nuestra vida está sometida a las leyes físicas, tal como las rocas. Pero hay una diferencia radical: somos materia orgánica que se desarrolla desde adentro. La roca seguirá ahí hasta que sea chocada o movida por otra materia (sea orgánica o inorgánica). Sin embargo, la simple materia orgánica sigue siendo parte del piso de abajo (Deleuze, 2012a). Lo que es propio del piso superior es la racionalidad. "En el Barroco el alma tiene con el cuerpo una relación compleja: siempre inseparable del cuerpo, encuentra en este una animalidad que le aturde, que la traba en los repliegues de la materia, pero también una humanidad orgánica o cerebral (el grado de desarrollo) que le permite elevarse, y la hará ascender a pliegues completamente distintos" (Deleuze, 2012a, pp. 21-22). Y aunque Deleuze no lo diga, no creo que la racionalidad a la que se refiere sea simplemente la de optimización de ganancias y la gestión de problemas. Esa capacidad humana cerebral también incluye la posibilidad de emocionarse, angustiarse o alegrarse.

En la obra de Caballero las figuras tienen la intensidad del estar sumidas en éxtasis, sea por la elevación o la caída de los cuerpos, transidas por el paso donde los pliegues de la materia mutan en los pliegues del alma, y viceversa. Los pliegues de la materia orgánica, presentados a través del exceso de la carne (el erotismo y la sexualidad) logran afectar los extremos de las cuerdas que sobresalen de la habitación cerrada, logran animar los pliegues interiores y nos mueven a una sensación de exultación. Nuevamente aparece la tensión entre la estética de la recepción y la estética de la creación, entre el ánima que despierta en el espectador y los perceptos que autoposicionan la obra. Las fuerzas que Caballero ha logrado captar en el movimiento de los cuerpos que desfallecen y se contorsionan agregan un grado de intensidad que anima al espectador y le ofrece algo que lo saca del atolladero de los pliegues de la materia. Ese es el límite de la estética de la creación: no todo percepto logra el despliegue del alma. El afecto trabaja entre los dos, ya que no sería posible ninguna afectación 
sin ese ser de sensaciones que es la obra, y que existe en sí. Al percepto le hace falta una intensidad que lo anime, una afección que lo saque de la nada sensible en la que cotidianamente nos movemos. Pero, al revés, no se puede mover el ánima sin la materia de los perceptos y la intensidad de los afectos.

La vida orgánica de aquellas almas llamadas a devenir racionales, a diferencia de las almas de los animales o las plantas, requiere de una violencia para despertarla de su letargo. En palabras de Lyotard, "el aistheton arranca lo inanimado del limbo donde no existe, horada su vacuidad con su rayo, y de ella hace surgir un alma. Un sonido, un olor, un color extraen del continuum neutro, del vacuum, la pulsación de un sentimiento" (1996, p. 166). Los aistheton de Caballero se mueven en una tensión entre contrarios que hacen parte del mismo mundo: cuerpo y alma, mortalidad e inmortalidad, emoción sensual y religiosidad (Ponce de León, 1991). Se trata de un pliegue de lo erótico en lo místico, de la profanación que mencionamos en párrafos anteriores, y a su vez de un pliegue de lo místico en lo erótico que eleva o hace yacer las figuras a través de la petit morte como acontecimiento sensible que anima el ánima.

Hasta aquí he avanzado en una de las principales tesis de este texto: el concepto de ánima. Ahora queda por articular este concepto con la otra tesis que me propongo defender: la estética mínima.

\section{El GESTO DE LO AUSENTE}

Si uno pudiera ser grande de verdad, si de verdad estuviéramos haciendo algo que vale la pena, algo que emocione, que ayude, que sirva para algo. No tener esa sensación constante de acto gratuito, esa inmensa vanidad de querer hacer soñar a los otros, o el placer de atormentarlos. Pero esa cosa grande, nueva, ese acto o esa obra que emocionen de verdad, los pintores no la hacen ni pueden hacerla (Caballero, 2014d, pp. 111-113)

La última etapa corresponde al final de la década de los ochenta y se prolonga hasta la muerte del artista, a causa de un síndrome cerebeloso, en 1995. Las obras de este periodo abandonan la técnica del dibujo para dar paso a un manejo más abstracto y expresivo. La línea se presenta cargada de energía, y las pinceladas de color se muestran como manchas tempestuosas. Hay un cambio de la representación realista al estilo del barroco y manierista, y cada vez más el cuerpo se difumina. Aunque la 
obra del artista colombiano durante algún tiempo mostró cuerpos que sufrían bajo posiciones forzadas y violentas, que según él eran una entrada de la violencia en Colombia dentro de su vida y obra, esto solo fue una transición para encontrar una estética de lo mínimo. Los afectos y perceptos del dolor y el sufrimiento empiezan a diseminarse. Se anuncia una estética de lo mínimo.

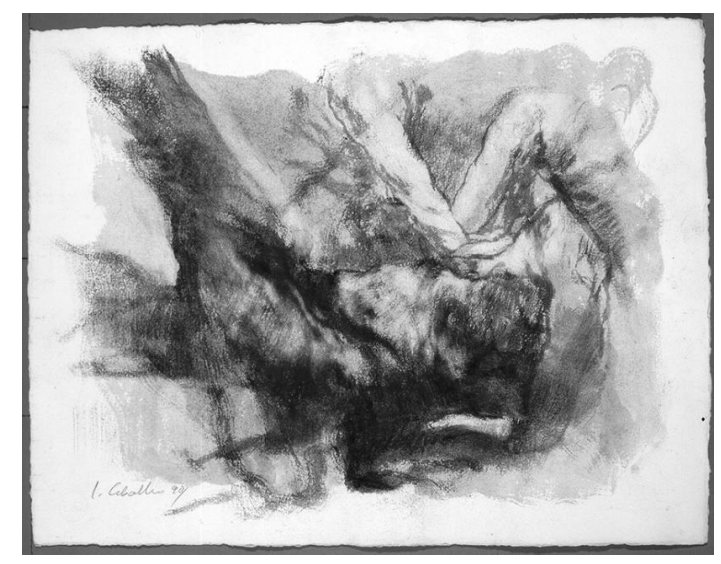

Fig. 3. Sin título, 1990. Óleo y pastel sobre papel. 34 X $43 \mathrm{~cm}$

El giro hacia una estética de lo mínimo no se puede entender si no se complementa con otro concepto que el propio Lyotard ofrece: lo sublime; Lyotard reelabora el concepto recurriendo a la concepción kantiana. Para Kant, el sentimiento de lo sublime encierra una contradicción, pues produce una sensación de pena y placer al mismo tiempo. La pregunta que se plantea es cómo se produce esa pena, pues es claro que el sentimiento de placer tiene su origen en el gusto. En la estética kantiana existen ciertos enunciados inteligibles (lo bello), a los cuales se corresponden ciertos casos (obra de arte) de la experiencia. Si la obra es bella, entonces, moverá a la aparición de la sensación de placer (gusto), sensación que es independiente de cualquier interés que la obra suscite en el espectador. Este planteamiento de lo bello no es otra cosa que la adaptación a la estética del principio ético del imperativo categórico. Como la sensación de placer se produce sin la mediación de ningún interés y sin ningún consenso entre los sujetos sobre lo que debe ser bello, la experiencia del placer no está regulada, y el sujeto tiene la capacidad reflexiva de concebir y presentar un objeto (obra de arte) que se corresponda con lo que él concibe como bello (Lyotard, 2003). El problema de la teoría kantiana es que deja en un limbo lo que se considera bello; es una teoría que ofrece una idea sin significación de lo bello. 
Por contraposición a la teoría del gusto, en lo sublime se produce un corto circuito, debido a que no se consigue establecer una imagen que se corresponda con el canon conceptual de lo bello. Pero ¿no habíamos dicho que la idea de lo bello se ofrecía en la estética kantiana como vacía de significación? Lyotard le sale al paso a esta dificultad teórica manifestando que ella no impidió que en la realidad social se le diera un contenido, un canon a lo bello ${ }^{2}$. Un ejemplo de la ausencia de correspondencia es la idea del mundo: tenemos una "Idea del mundo (la totalidad de lo que es), pero no tenemos la capacidad de mostrar un ejemplo de ella" (Lyotard, 2003, p. 21). Se pueden concebir los absolutos, como lo absolutamente grande o lo absolutamente bello, pero es imposible hacerlos ver, por lo que cualquier representación de ello se nos aparece como absolutamente insuficiente. Además, por contraposición al canon de lo bello, que ha sido producido consensualmente, lo sublime escapa a cualquier acuerdo, precisamente por la imposibilidad de cualquier representación. Las nociones de irrepresentabilidad e imposibilidad de consenso pueden ofrecer una clave de lectura del arte moderno, que ha demostrado ser inaprehensible por teorías omnicomprensivas que establecen criterios taxativos de lo que es y no es arte.

Frente al interrogante de cómo hacer patente ese absoluto, Caballero opta por una estética de la supresión, en la que el cuerpo empieza a desdibujarse, y solo quedan líneas de fuerza. Estas líneas son afectos, seres de sensacion escargados de una intensidad que no proviene únicamente de lo presentado en la obra. Otra vez estamos frente a la tensión entre creación y recepción, que revela otro límite de una estética basada en perceptos. Lo particular en la estética mínima consiste en que esos seres de sensaciones son apenas el pretexto para animar el ánima a través de las intensidades no siempre visibles de la afección. Este procedimiento es lo que Lyotard identifica con lo abstracto y la presentación negativa de lo sublime.

Con el concepto de lo sublime explicitado es posible entender la diferencia entre el pliegue barroco y la estética de lo mínimo. El pliegue barroco intenta ofrecer una representación positiva de los dos pisos, en la que se entrevé la elevación de los

2 En su aproximación al contenido de lo bello,Lyotard afirma que las obras que se consideran bellas eran creadas de acuerdo a una poética que estableció cánones que "legitimaban las obras destinadas a emocionar a la sociedad cortesana y a la comunidad de fieles, ambas formadas según esos cánones. Estos definían maneras fundadas sobre tal o cual concepción de la belleza ideal (que también eran las del bien)" (1996, p. 163). Por supuesto que ese ideal era un consenso tácito fruto del trabajo de mecenas, críticos de arte, artistas reconocidos e intelectuales. 
cuerpos con un alma que en medio de la saturación de la carne encuentra el camino al desplegamiento del ánima, a su movimiento. El procedimiento del barroco hace patente la existencia de los dos niveles de la casa, buscando la elevación de los cuerpos, la claridad de las almas racionales. Por su parte, el desvanecimiento del cuerpo y la reducción a líneas de fuerza animan el alma a través de lo ausente. Ya no se trata de pliegues materiales que muevan los extremos de la cuerda, sino de una presencia que nunca es presentable. ¿Qué es eso que está ausente? ¿Qué es lo irrepresentable? El sentimiento de la muerte, de la inercia, el vacuum. Aquí radica la paradoja de lo sensible: ofrece la muerte del alma a la vez que los aistheton, que nos animan a experimentar gozo o angustia, celebran lo sensible. El ánima solo existe afectada; sin esa sensación, sin ese acontecimiento sensible, permaneceríamos en los espacios-tiempos-materias que nuestra conciencia conoce y por los que transitamos sin pena ni gloria. "La sensación, que puede ser agradable o desagradable, anuncia no solamente placer o dolor, es decir, no sólo una calidad afectiva, sino que esta sensación también anuncia el alma que no existiría, que permanecería inanimada, si nada la afectara" (Lyotard, 2006, p. 127).

En Caballero, el gesto de reducir la paleta de colores, de sugerir formas que no se materializan del todo, de dejar en estado de suspensión tantos trazos fuertes, encierra una doble paradoja. Por un lado, está la paradoja de mostrar en lo sensible (que es lo que le promete la muerte al alma) una intensidad que anime, y, por el otro, recordarnos en la obra que la muerte del alma está en un sensible que el pintor no muestra. El pintor nos da a ver la muerte del ánima precisamente porque ella no está en la obra. ¡Sentimiento de angustia ante la amenaza de volver a la nada! En conclusión, el ánima en Caballero adquiere una dimensión doble y contradictoria: provocar una sensación especial (aminar) en el espectador, recordándole que al dejar de ver la obra volverá al estado inerme de la cotidianidad.

En busca del acontecimiento estético, Lyotard plantea una tensión entre querer morir y no querer morir. Para que el artista pueda encontrar ese color, sonido o figura que despierta el ánima debe conservar su alma impreparada a lo sensible y dispuesta a someterse (querer morir) al "acontecimiento sensible que pone el alma al desnudo, y que lo lanza plenamente a dolor y/o placer" (2006, p. 128). Ese servilismo a lo sensible se le antoja horroroso al artista, pero resulta necesario para que el alma no muera, ni regrese a la nada si no es afectada. En palabras del propio Caballero: “¿De qué sirve ganar el mundo si se pierde el alma?; pero también: ¿De qué sirve ganar el alma si se pierde el mundo?" (2014d, p. 113). 


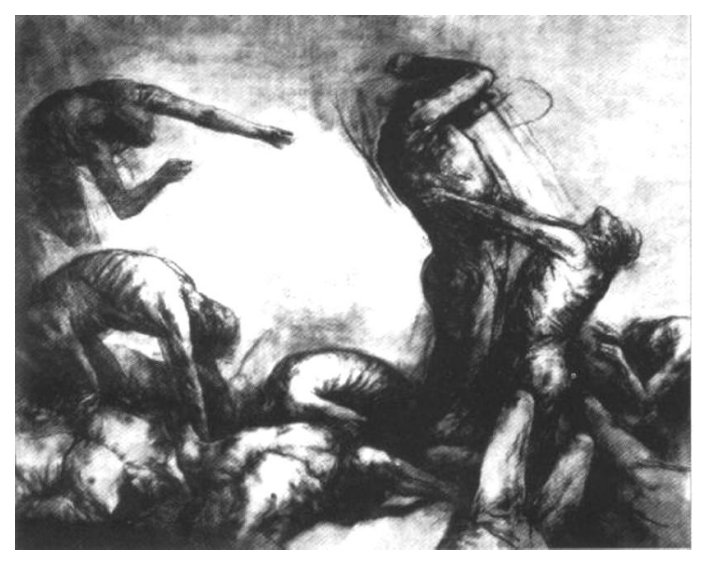

Fig. 4. Sin título, 1990. Carboncillo sobre papel. 600 x $600 \mathrm{~cm}$.

Este cambio en la obra de Caballero no fue intempestivo. A partir de 1985 inicia un proceso progresivo de desvanecimiento del cuerpo que coincide con la adopción de técnicas pictóricas inusuales y la producción de grandes formatos. El abandono del dibujo de trazo definido, técnica en la que Caballero había alcanzado un dominio impresionante, coincide con la exploración de medios en los que la definición del contorno de la figura se hace cada vez más difusa. La sanguina, el carboncillo y el pastel muestran áreas de color y líneas cargadas de una fuerza especial. Por otro lado, el gran formato usado en obras como la presentada en 1990, en la Galería Garcés-Velázquez, que medía seis por seis metros, permitía ver los trazos y las líneas de fuerza que convergían en la creación de varios cuerpos fantasmagóricos que solo eran apreciables tomando cierta distancia con respecto a la obra.

\section{Conclusiones}

El gran tamaño condiciona la forma, el tema, el color -o la ausencia de color-. La dificultad de realizar una imagen global que siga siendo sugestiva hace que lo realice en blanco y negro, es directo y a la vez. simbólico (porque el dibujo es ya en sí una abstracción). Me permite mostrar sin relatar, evitando que la escena pintada sea simplemente anecdótica. No se trata de representar la idea, o la imagen, sino de convertirla en una realidad pictórica

(Caballero, 1990)

Luis Caballero siempre detestó lo que él llamaba esteticismo, es decir, la pintura que se preocupa por la composición, la técnica y el color, pero a la que le da igual 
pintar un bodegón, una cafetera o un desnudo. Siguiendo la lectura que he propuesto de su obra, en sus inicios Caballero busca la creación de un ser de sensaciones siguiendo el estilo de Bacon; sin embargo, los cuadros de esta época aparecen recargados de elementos cromáticos, y se echa de menos la intensidad que logró el propio Bacon (Deleuze, 2002), intensidad fundamental para animar el ánima. Queda como tarea pendiente para un trabajo más conceptual aclarar lo que hay del afecto/afección deleuziano en la intensidad lyotardiana.

La interpretación que aquí se ofrece intenta mostrar que lo que definitivamente incomoda al pintor bogotano al momento de imitar a Bacon es la limitación propia de los perceptos concebidos en una estética de la creación en la que es suficiente crear un ser de sensaciones que se mantenga a sí . Caballero quiere que ese ser sea el primer paso, el pretexto para provocar un despertar del ánima en el espectador.

La evolución de Caballero lo lleva a una estética de lo mínimo, donde el dibujo sugerido y caótico, la paleta monocromática y las dimensiones de las obras ponen de manifiesto una doble paradoja: animar el alma a través de aquello que la condena a la muerte, pero haciendo que el espectador se enfrente a esa muerte que no está en la obra. Ya no se trata de un afecto de la muerte, pues es la muerte lo que precisamente no es en el ser de sensaciones de la obra. Caballero quiere hacer ver ese no ser de donde reemerge el ánima en cada obra. Siguiendo lo dicho por Lyotard, es posible afirmar que Caballero es un paladín del dios ciego de lo invisible, un dios que espera la asistencia de los pintores para hacer visible todo lo que él ve. "Pintar es hacer visible este invisible, es hacer visible lo que este dios ciego ve" (Lyotard, 2006, p. 129).

En este punto pueden plantearse algunos interrogantes que no serán cabalmente resueltos, pero que pueden ampliar la propia noción del pliegue barroco como una distribución de dos pisos: ¿Habrá un nuevo pliegue barroco, una nueva distribución en dos pisos? Alejarse de la obra implica ver la carne que sufre, acercarse hace ver sin mostrar (iparadoja!) la muerte del alma. Este nuevo pliegue distribuye una manifestación de las fuerzas (perceptos y afectos) que atraviesan la carne en el piso de abajo y una presentación del ánima que habita en el cuerpo como esa Cosa que no habla y parece estar arriba en una habitación cerrada, en un vacuum, esperando a que el acontecimiento sensible mueva los extremos de la cuerda en el piso de abajo. 


\section{REFERENCIAS}

Apollinaire, G. (2001). Alcoholes-El poeta asesinado. Madrid: Cátedra.

Caballero, L. (2014a). “Carta de mayo de 1968”. En: L. Caballero:¡Pobre de mí, no soy sino un triste pintor! (págs. 51-59). Bogotá: Universidad Jorge Tadeo Lozano.

Caballero, L. (2014b). "Carta del 17 de noviembre de 1969”. En L. Caballero, ¡Pobre de mí, no soy sino un triste pintor! (págs. 121-123). Bogotá: Universidad Jorge Tadeo Lozano.

Caballero, L. (2014c). “Carta del 20 de octubre de 1964”. En: L. Caballero, ¡Pobre de mí, no soy sino un triste pintor! (págs. 76-81). Bogotá: Universidad Jorge Tadeo Lozano.

Caballero, L. (2014d). “Carta sin fecha”. En: L. Caballero, ¡Pobre de mí, no soy sino un triste pintor! (págs. 109-113). Bogotá: Universidad Jorge Tadeo Lozano.

Caballero, L. (1995). "El cuerpo es lo que yo quiero decir”. En: L. Caballero, Luis Caballero. Bogotá: El Sello Editorial.

Caballero, L. (1990). La cuarta ambición. Bogotá: Galería Garcés Velásquez.

Caballero, L. (2010). Luis Caballero erótico. Bogotá: Villegas.

Deleuze, G. (1966). El abecedario de Gilles Deleuze. (C. Parnet, Entrevistador).

Deleuze, G. (2012). El pliegue: Leibniz y el barroco. Barcelona: Paidós.

Deleuze, G. (2002). Francis Bacon. Lógica de la sensación. Madrid: Arena Libros.

Deleuze, G., \& Guattari, F. (2013). ¿Qué es la filosofía? Barcelona: Anagrama.

Jaus, H. (1978. Experiencia estética y hermenéutica literarias. Madrid: Taurus.

Lyotard, J.-F. (2006). "La ceguera necesaria”. En: A. Chaparro, Los límites de la estética de la representación (págs. 121-139). Bogotá: Universidad del Rosario.

Lyotard, J.-F. (2003). La postmodernidad explicada a los niños. Barcelona: Gedisa. 
Lyotard, J.-F. (1996). Moralidades posmodernas. Madrid: Tecnos.

Malagón-Kurka, M. (2012). El deseo y el tormento secularizados en la obra de Luis Caballero. Bogotá: Banco de la República.

Ponce de León, C. (1991). "Los signos del cuerpo". En: B. L. Arango, Luis Caballero, Retrospectiva de una confesión. Bogotá: Banco de la República.

Segura, M. (1991). “Biografía resumida”.En: B. d.-B. Arango (Ed.), Luis Caballero: retrospectiva de una confesión (págs. 29-59). Bogotá: Banco de la República. 